\title{
Orthotropic hygro-mechanical behavior of Chinese fir during cyclical relative humidity variation
}

Hui Peng ${ }^{1,2}$, Jiali Jiang ${ }^{1 *}$, Jianxiong $\mathrm{Lu}^{1}$ and Jinzhen Cao ${ }^{2}$

\begin{abstract}
The orthotropic free swelling-shrinkage and mechano-sorptive creep (MSC) during cyclical relative humidity (RH) variation $(0-80 \% \mathrm{RH})$ and time-dependent viscoelastic creep (VEC) in a steady state $(0 \% \mathrm{RH})$ were examined in Chinese fir (Cunninghamia lanceolata). During RH changing, the occurrences of local maximum or minimum strains of the free swelling-shrinkage and MSC lagged behind the corresponding maximum or minimum RH. The lagged time decreased with increasing cyclical times. Furthermore, the lagged time exhibited an orthotropic behavior: the longer lagged time was found in longitudinal specimen compared to transverse specimens. MSC exhibited a more pronounced anisotropy than VEC. According to the three tests, the performance of free swelling-shrinkage and the mechano-sorptive effect on the orthotropic MSC behavior was addressed. The free swelling-shrinkage mainly dominated the creep strain during cyclic RH variation, especially for longitudinal specimen. The mechano-sorptive effect on the MSC behavior exerted more influence on tangential specimen compared to radial and longitudinal specimens. The mechano-sorptive limit was observed for all specimens. Longitudinal specimen required more cyclic times to approach the mechano-sorptive limit than transverse specimens.
\end{abstract}

Keywords: Orthotropic grain orientation, Mechanical stress, Cyclic relative humidity, Free swelling-shrinkage, Mechano-sorptive creep

\section{Introduction}

Wood by nature is hygroscopic. As a consequence, the response of its mechanical performance in structures to varying climate conditions is of particular interest. Mechanical response of wood to sustained loading (i.e., creep) is affected by the moisture content (MC) state [1-6]. The phenomenon, collectively referred to as hygro-mechanical behavior, includes free swellingshrinkage and coupling between mechanical stress and MC changes, i.e., mechano-sorptive (MS) effect [7]. As reported by Armstrong and Kingston [1], the MS effect advances creep considerably.

\footnotetext{
*Correspondence: jialiwood@caf.ac.cn

${ }^{1}$ Research Institute of Wood Industry of Chinese Academy of Forestry, Hunan Collaborative Innovation Center for Effective Utilizing of Wood \& Bamboo Resources, Beijing 100091, People's Republic of China Full list of author information is available at the end of the article
}

A numerical simulation of creep behaviors have to be known. Numerous investigations have been conducted by considering the MS characteristics of wood and wood composites [3, 7-13]. However, only few MS properties were observed for a given property-MC combination. So far, comprehensive data comprising the MC-dependent orthotropic MS behavior is missing. While the influence of MC on the MS behavior of wood in the longitudinal $(\mathrm{L})$ direction is relatively well known $[8,14-18]$, the behavior in the perpendicular to the grain (radial, $R$ and tangential, T), remains underexplored [19-23]. As tensile stress perpendicular to the grain represents the weakest timber point, its knowledge, especially as it relates to load capacity and failure prediction of wooden structures, is highly important in wood engineering. Most importantly, knowledge of orthotropic MS behavior is essential in the wood industry, particularly in the hygro-mechanical treatment efficiency. Notably orthotropic MS creep 
(MSC) parameters are also essential input parameters for computational models used in civil engineering.

The present study was aimed at characterizing the orthotropic hygro-mechanical behavior during cyclical relative humidity $(\mathrm{RH})$ variation under tensile load. The time-dependent viscoelastic creep in a steady state (i.e., VEC), free swelling-shrinkage and MSC tests under RH cycles were performed in Chinese fir (Cunninghamia lanceolata) in $\mathrm{L}, \mathrm{R}$ and $T$ grain orientations. The distinct response of orthotropic MS behavior to cyclic $\mathrm{RH}$ variation was addressed. The contribution of free swelling-shrinkage and MS effect to the orthotropic MSC was expected to be quantitatively analyzed.

\section{Materials and methods}

\section{Materials}

A 25-year-old Chinese fir was selected. Clear specimens with $\mathrm{L}, \mathrm{R}$, and $T$ grain orientations were cut into a size of $35 \mathrm{~mm} \times 6 \mathrm{~mm} \times 1.5 \mathrm{~mm}$ within the no. $6-14$ growth rings (heartwood), see Fig. 1. Before testing, all specimens were dried in a sealed container over pentoxide at $30{ }^{\circ} \mathrm{C}$ for more than 9 weeks until a constant mass was achieved. The $\mathrm{MC}$ of the dried specimens was around $0.6 \%$. In addition, specimens conditioned at $80 \% \mathrm{RH}$ were also prepared to determine the tensile stress used for MSC tests. The $80 \% \mathrm{RH}$ conditions was attained via the humidification method over pentoxide or sulfuric acid [19], and the corresponding equilibrium MC (EMC) was about $14.1 \%$.

\section{Methods}

Tensile tests were conducted by a dynamic mechanical analyzer (DMA Q800, TA Instruments) equipped with a DMA-RH accessory. The distance between the clamps was ca. $17 \mathrm{~mm}$. After being mounted on the clamp in the testing chamber, the specimens were equilibrated at $0 \% \mathrm{RH}$ for $60 \mathrm{~min}$ prior to the actual measurements. Straight specimens were obtained by a brief application of a preload of $0.01 \mathrm{~N}$.

Three groups of tests were carried out to enable separation of the principal components of strains. The first test

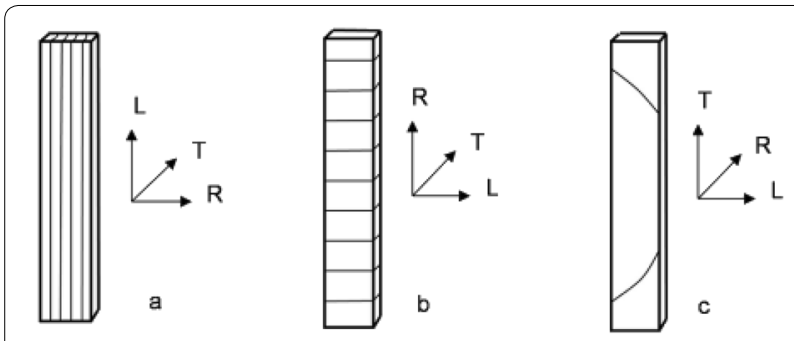

Fig. 1 Specimens in $\mathbf{a} L, \mathbf{b} R$ and $\mathbf{c} T$ grain orientations group consisted of simultaneous measurement of $\mathrm{MC}$ changes and the free swelling-shrinkage deformation, being monitored on unloaded specimens subjected to the cycling changes of RH. In the second test group, the MSC deformation of specimen subjected to load and the same climate changes as for free swelling-shrinkage was measured. The last group was used to conduct the timedependent VEC tests under a steady state.

\section{Free swelling-shrinkage tests during the cyclical $R H$}

The separate unloaded $L, R$ and $T$ specimens were used to monitor free swelling-shrinkage deformation. $\mathrm{RH}$ in the DMA chamber was firstly increased from 0 to $80 \%$ $\mathrm{RH}$ with the ramping rate of $2.0 \% \mathrm{RH} \mathrm{min} \mathrm{m}^{-1}$ (Fig. 2), and a moisture adsorption was then performed until adsorption time reached $60 \mathrm{~min}$. The $\mathrm{RH}$ was set back to $0 \%$, and a desorption process was, therefore, conducted subsequently for another $60 \mathrm{~min}$. The above moisture change cycle (adsorption-desorption) was then repeated 5 times. Totally, 6 moisture change cycles were performed in one test. In addition, MC was measured by weighing specimens before and after $\mathrm{MC}$ changes. The time points for monitoring $\mathrm{MC}$ were marked by symbols in Fig. 2. Five replicates were performed for each test.

\section{MSC tests during the cyclical $R H$}

The specimens subjected to load and MC changes were used to examine MSC. The RH changing procedure was the same as displayed in Fig. 2. Based on stress/strain sweeps in $14.1 \%$ EMC samples under $80 \% \mathrm{RH}$, the ultimate tensile stress of $L$ specimen was not reached due to the 2.1 MPa maximum stress of DMA Q800; therefore, the stress value of $1.3 \mathrm{MPa}$ was selected. In the case of $R$ and $T$ specimens, the stress level was set as $20 \%$ of ultimate tensile stress (1.7 $\mathrm{MPa}$ in $R$ and $0.45 \mathrm{MPa}$ in $\mathrm{T})$, i.e.,

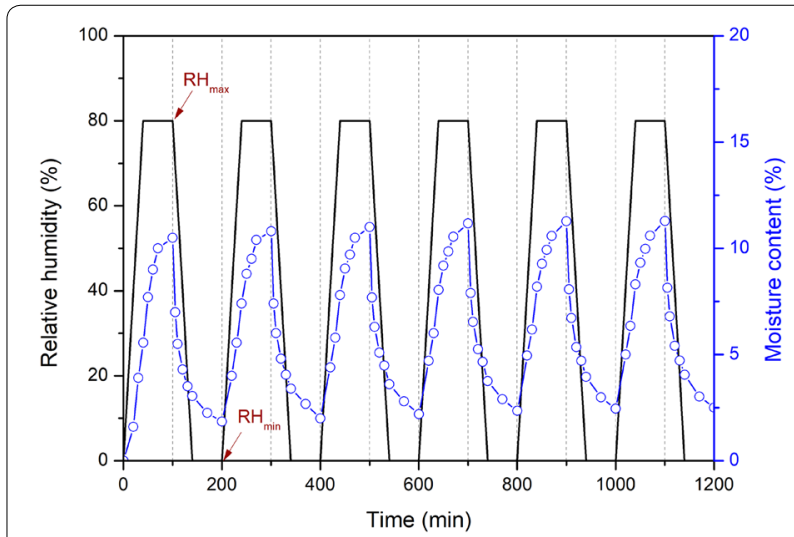

Fig. 2 Plots of relative humidity $(\mathrm{RH})$ and moisture content (MC) against cyclic time for Chinese fir 
as $0.34 \mathrm{MPa}$ and $0.09 \mathrm{MPa}$ for the $R$ and $T$ specimens, respectively.

\section{VEC tests under steady state}

The specimens subjected to load under a constant $0 \%$ RH condition were used to measure the 1200-min VEC behaviors. The stress for VEC tests is the same as for MSC tests. Five replicates were performed for each test, and the results were shown by the average values of the five measurements.

\section{Results and discussion}

\section{Orthotropic free swelling-shrinkage}

The coefficient of variation in MC among the $L, R$ and $T$ specimens was less than $5 \%$. The average MC evolution during the cyclical $\mathrm{RH}$ variation is presented in Fig. 2. Moisture uptake or loss below the fiber saturation point is always accompanied by dimensional changes, i.e., by free swelling or shrinkage (Fig. 3). The standard deviation of the free swelling-shrinkage was approximately $3 \%$ of the average values for each orientation. For all specimens, the swelling-shrinkage displayed fluctuated with the change of MC: increased with increase of MC and decreased with the decreasing MC (Figs. 2, 3).

The orthotropic swelling-shrinkage is visible in Fig. 3. The $L$ swelling-shrinkage was quite low, and the $T$ swelling-shrinkage was 1.5 times higher than that of the $R$ swelling-shrinkage. The cell orientation in the $L$ direction determined the lower free swelling-shrinkage for $L$ specimens. The wood cell wall is a composite biopolymer consisting of cellulose microfibrils (CMFs) and lignin-hemicellulose matrix [24-26]. The CMFs, which dominate the mechanical properties of $L$ specimen, are by orders of magnitude stiffer than the matrix and largely unaffected by water sorption, i.e., they do not swell or shrink [27-29]. Thus, the stiff CMFs restrict the swelling-shrinkage in the $L$ direction. Furthermore, the mechanisms governing the differential swelling-shrinkage behavior between the $R$ and $T$ specimens have been largely concerned, which can be subdivided into three groups: restriction of ray tissues [30,31]; the interaction between earlywood and latewood [32]; and the microfibril angle in the $\mathrm{S}_{2}$ layer [30].

During the cyclical progress, 6 times of local maximum or local minimum strains of free swelling-shrinkage ( $\varepsilon_{\max }^{\alpha}$ and $\varepsilon_{\min }^{\alpha}$, respectively) alternately occurred (Fig. 3). The occurrences of $\varepsilon_{\max }^{\alpha}$ and $\varepsilon_{\min }^{\alpha}$ lagged behind the corresponding maximum or minimum values of $\mathrm{RH}\left(\mathrm{RH}_{\max }\right.$, $80 \% \mathrm{RH}$ or $\left.\mathrm{RH}_{\min }, 0 \% \mathrm{RH}\right)$. The $\mathrm{RH}_{\min }$ or $\mathrm{RH}_{\max }$ are considered as the $\mathrm{RH}$ after 60 -min isohume conditioning, as marked in Fig. 2. The fact that water molecular move into or out wood cell walls contributed the fluctuated free swelling-shrinkage. Since the water diffusion speed
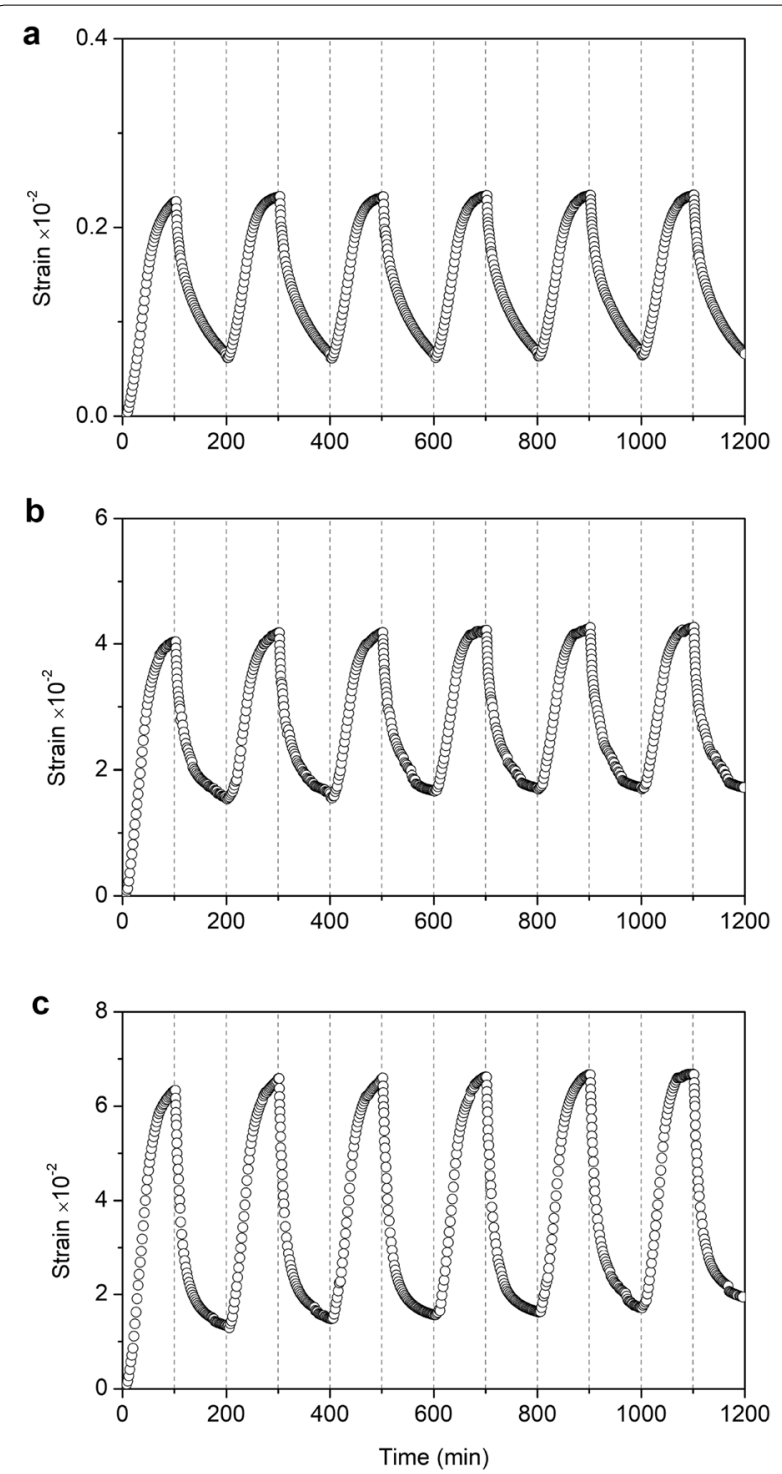

Fig. 3 Changes of free swelling-shrinkage strain during the cyclical relative humidity variation for a longitudinal, $\mathbf{b}$ radial and $\mathbf{c}$ tangential specimens

was slower than the $\mathrm{RH}$ changing rate, the occurrences of $\varepsilon_{\max }^{\alpha}$ and $\varepsilon_{\min }^{\alpha}$ lagged behind $\mathrm{RH}_{\max }$ or $\mathrm{RH}_{\min }$.

Table 1 lists the lagged time of $\varepsilon_{\max }^{\alpha}$ and $\varepsilon_{\min }^{\alpha}$ during 6 times of RH cycles for $\mathrm{L}, R$ and $T$ specimens. It was revealed that the lagged time between occurrences of $\varepsilon_{\max }^{\alpha}$ or $\varepsilon_{\min }^{\alpha}$ and corresponding $\mathrm{RH}_{\max }$ or $\mathrm{RH}_{\min }$ decreased and leveled off with the increasing cycle time, regardless of grain orientation, in agreement with earlier studies [33, 34]. The lagged time for $L$ specimen was longest, followed by $R$ and $T$ specimens. The distinct response of lagged time for transverse specimens is consistent with previous studies [35]. These results may be 
Table 1 Changes in local maximum or minimum value of free swelling-shrinkage $\left(\varepsilon^{a}\right)$ during the cyclical relative humidity variation

\begin{tabular}{lllll}
\hline $\begin{array}{l}\text { Local maximum } \\
\text { or minimum value of } \boldsymbol{\varepsilon}^{\boldsymbol{\alpha}}\end{array}$ & $\begin{array}{l}\text { Occurred } \\
\text { sequency }\end{array}$ & \multicolumn{3}{l}{ Lagged time (min) } \\
\cline { 3 - 5 } & & $\boldsymbol{L}$ & $\boldsymbol{R}$ & $\boldsymbol{T}$ \\
\hline$\varepsilon_{\max }^{\alpha}$ & 1 & 3.80 & 2.62 & 2.22 \\
& 2 & 3.53 & 2.42 & 2.02 \\
& 3 & 3.01 & 2.12 & 1.92 \\
& 4 & 2.72 & 2.02 & 1.87 \\
& 5 & 2.69 & 1.92 & 1.85 \\
& 6 & 2.60 & 1.94 & 1.82 \\
$\varepsilon_{\min }^{\alpha}$ & 1 & 4.11 & 3.02 & 2.51 \\
& 2 & 3.62 & 2.79 & 2.33 \\
& 3 & 3.06 & 2.42 & 2.21 \\
& 4 & 3.02 & 2.29 & 2.12 \\
& 5 & 3.03 & 2.14 & 2.03 \\
& 6 & 2.98 & 2.11 & 2.05 \\
\hline
\end{tabular}

Lagged time $=t_{\varepsilon^{\alpha}} \quad-t_{\mathrm{RH}}{ }_{\max \min }$; the $\mathrm{RH}_{\max \min }$ are considered as the $\mathrm{RH}$ after 60-min isohume conditioning, as marked in Fig. 2

related to the swelling-shrinkage properties of CMFs and matrix during $\mathrm{MC}$ variation [36]. The distinct responses of CMFs and matrix to the varying $\mathrm{MC}$ results in a phase lag of dimensional changes between these two parts [34]. With the cyclic RH changes, polymers asymptotically returned to a dynamic equilibrium state, and the phase lag between CMFs and matrix could be decreased. When compared with $R$ and $T$ specimens, the higher steric hindrance of the $L$ specimen, due to the orientation of highly crystalline CMFs in the $L$ direction [37], caused that the $L$ specimen took a longer time to approach the dynamic equilibrium state (i.e., longer lagged time for $L$ specimen).

\section{Orthotropic MSC}

The total strain during a creep experiment consisted of both the elastic strain and the creep strain. At times shorter than $3 \mathrm{~s}$, the strain on samples included elastic strain, which develops during uploading. The elastic strain was $0.0001,0.0006$ and 0.0005 for $\mathrm{L}, R$ and $T$ specimen, respectively. The creep strain dominates at loading times $>3 \mathrm{~s}$, as shown in Fig. 4. Both elastic and creep strains exhibited a dependence on the orthotropic grain orientation, especially for creep strain. The creep strain in $T$ direction was 33.8 and 13.0 times higher than that in $L$ direction for MSC and VEC tests after 1200-min tests, respectively (Fig. 4), indicating that MC changes affected the creep anisotropy. The creep strain in the MSC test was clearly larger than that in the VEC test, irrespective of grain orientations. In addition, Fig. 4 presents that the response of MSC to cyclical RH changes was fluctuated as well, similar
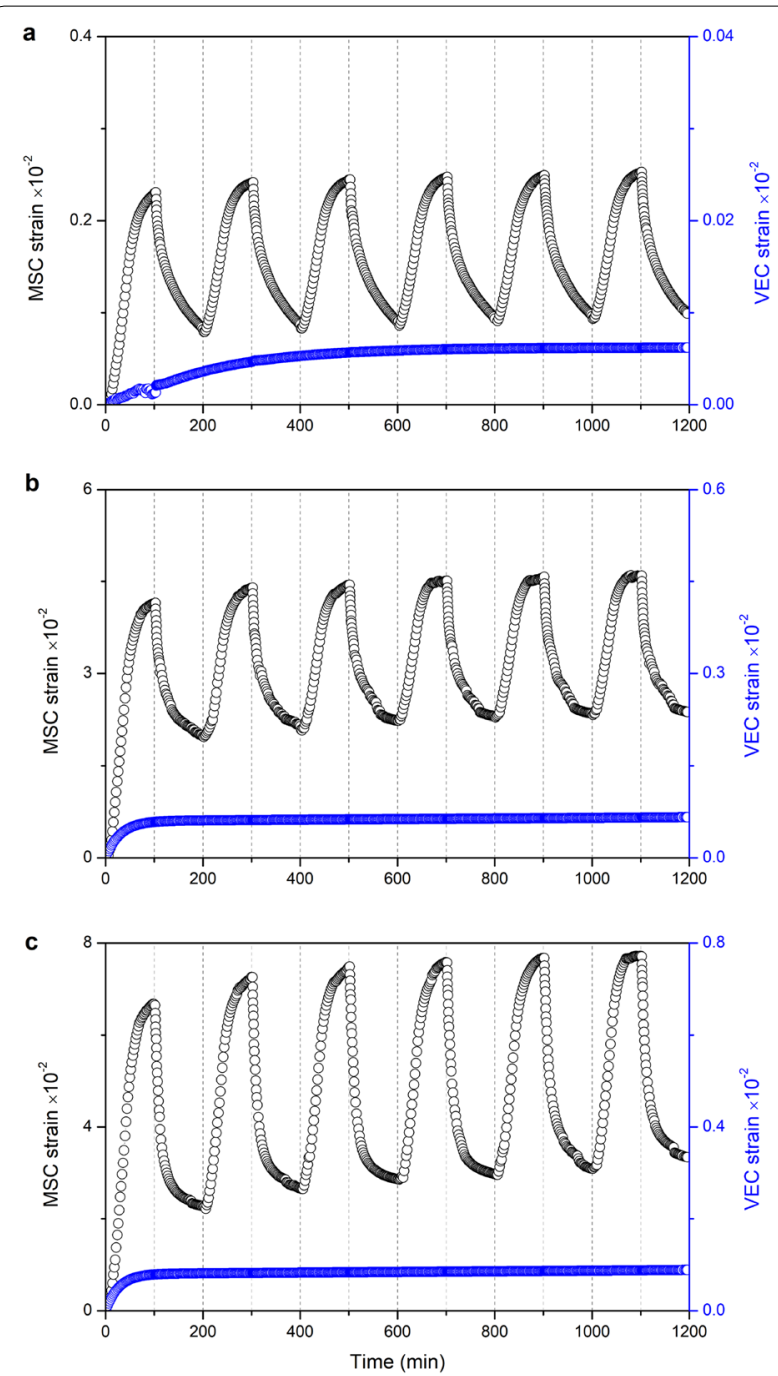

Fig. 4 Changes of mechano-sorptive creep (MSC) strain during the cyclical relative humidity variation and time-dependent viscoelastic creep (VEC) strain at steady state $(0 \% \mathrm{RH})$ for a longitudinal, b radial and $\mathbf{c}$ tangential specimens

to the responses of free swelling-shrinkage. There are local maximum or local minimum strains of MSC $\left(\varepsilon_{\max }\right.$ and $\varepsilon_{\min }$, respectively). Moreover, combinations of $\varepsilon_{\max }$ and $\varepsilon_{\max }^{\alpha}$ or $\varepsilon_{\min }$ and $\varepsilon_{\min }^{\alpha}$ arise simultaneously behind the corresponding $\mathrm{RH}_{\max }$ or $\mathrm{RH}_{\text {min }}$.

Generally, the creep strain under variable environmental conditions is assumed to be composed of three distinct contributions. The first is the time-dependent viscoelastic strain, i.e., VEC in a steady state. The second is free swelling-shrinkage strain caused by MC change, and the third arises from the coupling effects between the mechanical stress and the MC changes, i.e., MS effect. MS effect is attributed to unstable state in wood cell walls [21-23]. Several causes of instability 
have been considered. One possible explanation is the transient redistributions of stresses caused by the anisotropic hygroexpansion [38, 39], and another explanation is the redistributions of stresses attributed to sorption-induced stress gradients [40]. After considering a molecular interpretation of the mechanism, Gibson [41] postulated that the reciprocated diffusion of water into and out of wood cell walls leads to the continuous breaking and reforming of hydrogen bonds within the wood cell wall. Takemura $[42,43]$ believed that desorption of water molecules provides spaces contributing to a higher mobility between molecular chains. Furthermore, transient hydrogen bonds create or eliminate the free volume in wood cell wall, disturbing the equilibrium state of the molecular packing mode [7]. Under an external load, the unstable state enhances the flexibility of the polymer network and causes the MS effect.

As is visible from Figs. 3 and 4, the magnitude of the strains in MSC is higher than that in free swellingshrinkage. A high ratio of free swelling-shrinkage to MSC strain, $\varepsilon_{i}^{\alpha} / \varepsilon_{i}$, was found for all grain orientations specimens (Table 2). This agrees with earlier studies [7, 19, 20] indicating that the majority of strain in MSC is expansion. Quite frequently, only separation of the effect of free shrinkage/swelling are reported and analyzed, while the MS effect is neglected without proper justification $[7,15]$. In order to analyze the contribution of MS effect to the orthotropic creep behavior quantitatively, a "MS strain $\left(\varepsilon^{\mathrm{ms}}\right)$ " obtained by subtracting the free swelling-shrinkage $\left(\varepsilon^{\alpha}\right)$ and time-dependent VEC strain $\left(\varepsilon^{\mathrm{ve}}\right)$ in a steady state from the MSC strain $(\varepsilon)$ has the appearance:

$$
\varepsilon^{\mathrm{ms}}(t)=\varepsilon(t)-\varepsilon^{\alpha}(t)-\varepsilon^{\mathrm{ve}}(t) .
$$

The MS strain evolutions are shown in Fig. 5. It was obvious that after each cycle the MS strain increased, regardless of grain orientation. Table 2 shows the ratio
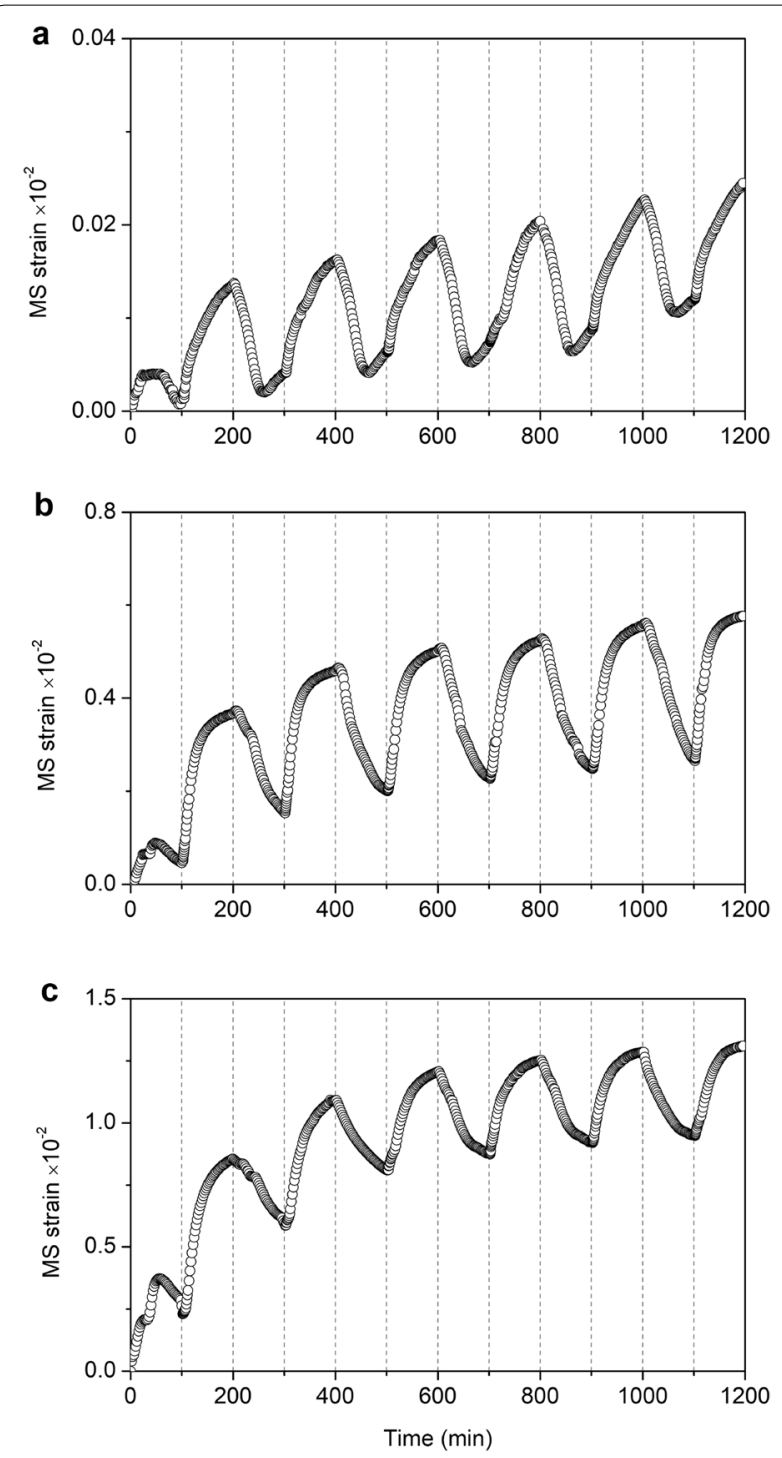

Fig. 5 Changes of mechano-sorptive (MS) strain during the cyclical relative humidity variation for a longitudinal, $\mathbf{b}$ radial and $\mathbf{c}$ tangential specimens

Table 2 Ratios of free swelling-shrinkage to mechano-sorptive creep strain $\left(\varepsilon_{i}^{a} / \varepsilon_{i}\right)$ and mechano-sorptive strain to mechano-sorptive creep strain $\left(\varepsilon_{i}^{\mathrm{ms}} / \varepsilon_{i}\right)$ determined at the end of each cyclical relative humidity variation

\begin{tabular}{|c|c|c|c|c|c|c|}
\hline \multirow[t]{2}{*}{ Occurred sequency } & \multicolumn{3}{|c|}{$\varepsilon_{i}^{\alpha} / \varepsilon_{i}\left(\times 10^{-2}\right)$} & \multicolumn{3}{|c|}{$\varepsilon_{i}^{\mathrm{ms}} / \varepsilon_{i}\left(\times 10^{-2}\right)$} \\
\hline & $L$ & $R$ & $T$ & $L$ & $R$ & $T$ \\
\hline 1 & 78.95 & 78.36 & 58.88 & 15.96 & 19.31 & 38.22 \\
\hline 2 & 75.36 & 75.68 & 55.88 & 18.51 & 21.66 & 40.81 \\
\hline 3 & 73.18 & 74.75 & 54.85 & 20.27 & 22.58 & 41.65 \\
\hline 4 & 71.67 & 74.44 & 54.96 & 21.80 & 22.94 & 41.92 \\
\hline 5 & 70.21 & 73.50 & 55.63 & 23.37 & 23.92 & 42.31 \\
\hline 6 & 69.00 & 72.89 & 55.37 & 24.81 & 24.59 & 42.57 \\
\hline
\end{tabular}

$i$ is occurred sequency 
of MS strain to MSC strain, $\varepsilon_{i}^{\mathrm{ms}} / \varepsilon_{i}$, determined the end of each cyclical relative humidity variation. The $\varepsilon_{i}^{\mathrm{ms}} / \varepsilon_{i}$ increased with the increasing cyclic time, indicating the humidity cycle promoted the contribution of mechanical stress in the MSC behavior. Moreover, $\varepsilon_{i}^{\mathrm{ms}} / \varepsilon_{i}$ demonstrated an anisotropy (Table 2); that is, the value of $\varepsilon_{i}^{\mathrm{ms}} / \varepsilon_{i}$ for $L$ specimen was distinctly lower than that for $T$ specimen. Therefore, the coupling effects between the mechanical stress and the MC changes exerted more influence on the $T$ specimen compared to $R$ and $L$ specimens.

To compare the orthotropic MS strain corresponding to each complete cycle, the MS-trajectory curves (MS strain versus MC) were plotted from the results in Fig. 5, as shown in Fig. 6. These trajectories, which eliminate time, allow the discussion on the MC-dependent orthotropic MS strain during the adsorption-desorption process. Figure 6 confirms that when the MC was cycled, the corresponding MS strain increment gradually decreased so that on this basis the existence of a MS limit appeared plausible. The results were consistent with those previously given by Navi [7]. In addition, the increasing rate of MS strain after each cycle is presented in Fig. 7. It was obvious that the increasing rate of MS strain decreased as cycled MC. With the cyclic changes of RH, the unstable state within the wood cell wall is relaxed and polymers can be stabilized due to the reorientation of molecular chains [22,34], resulting in a decrease in the increasing rates of MS strain.

Figure 7 shows a greater increasing rate of MS strain for $L$ specimen than for transverse specimens, indicated that the more cyclic times are required for $L$ specimen to approach the MS limit. The result is related to the steric hindrance of molecular motion. In tensile mode, the steric hindrance of the $L$ specimen is clearly higher than that of the transverse specimens because of the orientation of highly crystalline CMFs in the $L$ direction [37], which means that the $L$ specimen takes a longer time to approach new dynamic equilibrium state.

\section{Conclusion}

The orthotropic hygro-mechanical characteristics of Chinese fir under cyclic RH conditions were investigated. Free swelling-shrinkage and MSC behaviors fluctuated with cyclic $\mathrm{RH}$, but lagged behind the imposed RH. The lagged time decreased with increasing cyclic periods. Furthermore, the lagged time showed a close relationship with anatomy structure of wood: transverse specimens had a shorter lagged time than $L$ specimen. Based on the datasets of VEC in steady state and MSC under RH cycles, it seems like that the creep anisotropy of MSC was more pronounced than that of
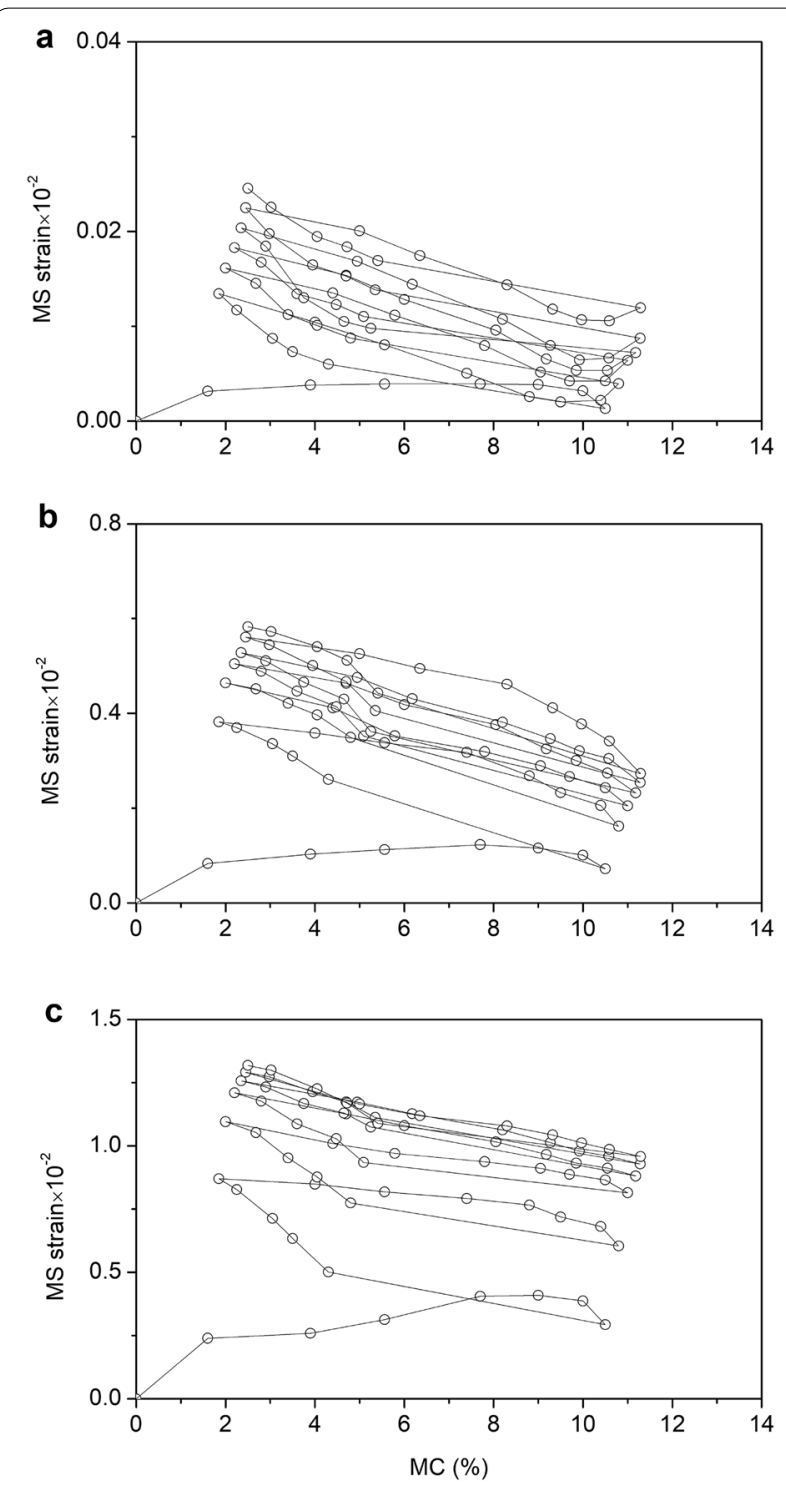

Fig. 6 Mechano-sorptive (MS) strain trajectories versus moisture content (MC) for a longitudinal, $\mathbf{b}$ radial and $\mathbf{c}$ tangential specimens

VEC. The VEC, free swelling-shrinkage and MSC data offered an opportunity to calculate the performance of free swelling-shrinkage and the MS effect on the orthotropic MSC behavior, respectively. The majority of strain in MSC is free swelling-shrinkage, especially in the axial direction. The MS strain, arising from the coupling effects between the mechanical stress and the MC changes, exerted more influence on $T$ specimen compared to $R$ and $L$ specimens. The MS strain trajectories evidenced the existence of MS limit. Moreover, $L$ specimen required more cyclic times to approach the MS limit than transverse specimens. 


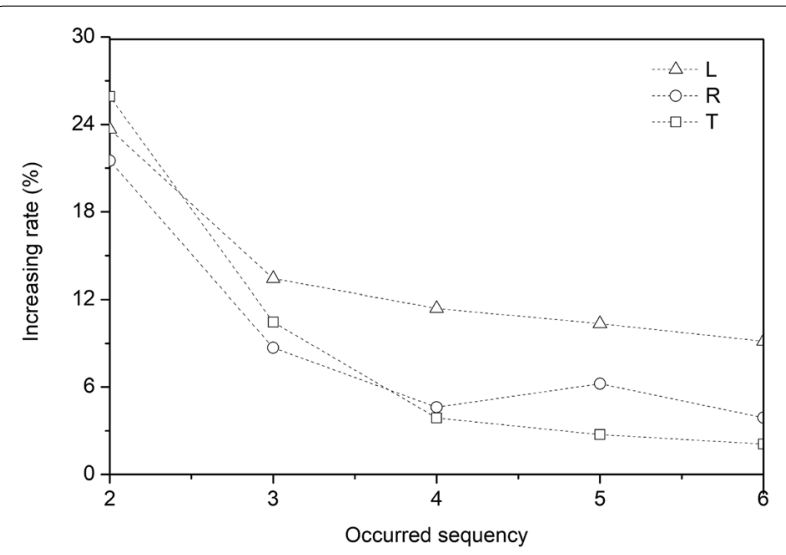

Fig. 7 The increasing rate of mechano-sorptive (MS) strain during the cyclical relative humidity variation for longitudinal $(L)$, radial $(R)$ and tangential $(T)$ specimens. Increasing rate $=\left(\varepsilon_{i}^{\mathrm{ms}}-\varepsilon_{i-1}^{\mathrm{ms}}\right) / \varepsilon_{i-1}^{\mathrm{ms}} \times 100 \%, i$ is occurred sequency

\section{Abbreviations}

CMF: Cellulose microfibrils; EMC: Equilibrium moisture content; L: Longitudinal; MC: Moisture content; MS: Mechano-sorptive; MSC: Mechano-sorptive creep; R: Radial; RH: Relative humidity; T: Tangential; VEC: Viscoelastic creep.

\section{Acknowledgements}

The authors are grateful for the financial support from the National Natural Science Foundation of China (31570548).

\section{Authors' contributions}

$\mathrm{HP}, \mathrm{JL}$ and $\mathrm{JC}$ conceived and designed the experiments; HP and JJ performed the experiments and wrote the manuscript. All authors read and approved the final manuscript.

\section{Funding}

This research was sponsored by the National Natural Science Foundation of China (31570548).

\section{Availability of data and materials}

The datasets used and/or analyzed during the current study are available from the corresponding author on reasonable request.

\section{Competing interests}

The authors declare that they have no competing interests.

\section{Author details}

${ }^{1}$ Research Institute of Wood Industry of Chinese Academy of Forestry, Hunan Collaborative Innovation Center for Effective Utilizing of Wood \& Bamboo Resources, Beijing 100091, People's Republic of China. ${ }^{2}$ College of Materials Science and Technology, Beijing Forestry University, Beijing 100083, People's Republic of China.

\section{Received: 3 September 2019 Accepted: 3 March 2020}

Published online: 12 March 2020

\section{References}

1. Armstrong L, Kingston R (1960) Effect of moisture changes on creep in wood. Nature 185:862-863

2. Armstrong L, Christensen G (1961) Influence of moisture changes on deformation of wood under stress. Nature 191:869-870

3. Navi P, Stanzl-Tschegg S (2009) Micromechanics of creep and relaxation of wood. A review COST Action E35 2004-2008: wood machining-micromechanics and fracture. Holzforschung 63:186-195
4. Salmén L, Burgert I (2009) Cell wall features with regard to mechanical performance. A review COST Action E35 2004-2008: wood machiningmicromechanics and fracture. Holzforschung 63:121-129

5. Gao S, Wang L, Wang X (2014) The influence of temperature and moisture contents on modulus of elasticity of Pinus koraiensis wood. J For Eng 28:38-42

6. Yang R, Zhou D, Wang S, Zhang Y, Mao H (2014) Effects of hydrophobic modification on wood nanomechanical properties of Chinese fir. J For Eng 28:78-81

7. Navi P, Pittet V, Plummer CJG (2002) Transient moisture effects on wood creep. Wood Sci Technol 36:447-462

8. Huang Y (2016) Creep behavior of wood under cyclic moisture changes: interaction between load effect and moisture effect. J Wood Sci 62:392-399

9. Dong F, Olsson A-M, Salmén L (2010) Fibre morphological effects on mechano-sorptive creep. Wood Sci Technol 44:475-483

10. Olsson A-M, Salmén L (2014) Mechano-sorptive creep in pulp fibres and paper. Wood Sci Technol 48:569-580

11. Olsson A-M, Salmén L, Eder M, Burgert I (2007) Mechano-sorptive creep in wood fibres. Wood Sci Technol 41:59-67

12. Zhan T, Jiang J, Lu J, Zhang Y, Chang J (2019) Frequency-dependent viscoelastic properties of Chinese fir (Cunninghamia lanceolata) under hygrothermal conditions. Part 1: moisture adsorption. Holzforschung 73:727-736

13. Zhan T, Jiang J, Lu J, Zhang Y, Chang J (2019) Frequency-dependent viscoelastic properties of Chinese fir (Cunninghamia lanceolata) under hygrothermal conditions. Part 2: moisture desorption. Holzforschung 73:737-746

14. Muszyński L, Lagana R, Shaler SM (2006) Hygro-mechanical behavior of red spruce in tension parallel to the grain. Wood Fiber Sci 38:155-165

15. Muszyński L, Lagana R, Shaler SM, Davids W (2005) Comments on the experimental methodology for determination of the hygro-mechanical properties of wood. Holzforschung 59:232-239

16. Saifouni O, Destrebecq J-F, Froidevaux J, Navi P (2016) Experimental study of the mechanosorptive behaviour of softwood in relaxation. Wood Sci Technol 50:789-805

17. Zhan T, Jiang J, Lu J, Zhang Y, Chang J (2018) Influence of hygrothermal condition on dynamic viscoelasticity of Chinese fir (Cunninghamia lanceolata). Part 1: moisture adsorption. Holzforschung 72:567-578

18. Zhan T, Jiang J, Lu J, Zhang Y, Chang J (2018) Influence of hygrothermal condition on dynamic viscoelasticity of Chinese fir (Cunninghamia lanceolata). Part 2: moisture desorption. Holzforschung 72:579-588

19. Peng H, Jiang J, Lu J, Cao J (2018) Orthotropic mechano-sorptive creep behavior of Chinese fir during the moisture adsorption process determined in tensile mode via dynamic mechanical analysis (DMA). Holzforschung 73:229-239

20. Peng H, Jiang J, Lu J, Cao J (2019) Orthotropic mechano-sorptive creep behavior of Chinese fir during moisture desorption process determined in tensile mode. Wood Sci Technol 53:747-764

21. Takahashi C, Ishimaru Y, lida I, Furuta Y (2004) The creep of wood destabilized by change in moisture content. Part 1: the creep behaviors of wood during and immediately after drying. Holzforschung 58:261-267

22. Takahashi C, Ishimaru Y, lida I, Furuta Y (2005) The creep of wood destabilized by change in moisture content. Part 2: the creep behaviors of wood during and immediately after adsorption. Holzforschung 59:46-53

23. Takahashi C, Ishimaru Y, lida I, Furuta Y (2006) The creep of wood destabilized by change in moisture content. Part 3: the influence of changing moisture history on creep behavior. Holzforschung 60:299-303

24. Salmén $L$ (2004) Micromechanical understanding of the cell-wall structure. C R Biol 327:873-880

25. Peng H, Jiang J, Lu J, Cao J (2017) Application of time-temperature superposition principle to Chinese fir orthotropic creep. J Wood Sci 63:455-463

26. Lu J, Peng H, Cao J, Jiang J, Zhao R, Gao Y (2018) Application of dynamic mechanical analysis in wood science research. J For Eng 3:1-11

27. Hill CAS, Norton A, Newman G (2009) The water vapor sorption behavior of natural fibers. J Appl Polym Sci 112:1524-1537

28. Schulgasser K, Witztum A (2015) How the relationship between density and shrinkage of wood depends on its microstructure. Wood Sci Technol 49:389-401

29. Liu Y, Zhang M, Guan M (2016) A NMR study on wood moisture sorption. J For Eng 1:49-53 
30. Bonarski JT, Kifetew G, Olek W (2015) Effects of cell wall ultrastructure on the transverse shrinkage anisotropy of Scots pine wood. Holzforschung 69:501-507

31. Skaar C (1988) Wood-water relations. Springer Verlag, Berlin

32. Pentoney R (1953) Mechanisms affecting tangential vs. radial shrinkage. J Forest Prod Res Soc 3:27-32

33. Chomcharn A, Skaar C (1983) Dynamic sorption and hygroexpansion of wood wafers exposed to sinusoidally varying humidity. Wood Sci Technol 17:259-277

34. Zhan T, Jiang J, Lu J, Peng H (2015) Dynamic viscoelastic properties of Chinese fir under cyclical relative humidity variation. J Wood Sci 61:465-473

35. Ma E-n, Zhao G-j, Cao J-z (2005) Hygroexpansion of wood during moisture adsorption and desorption processes. Forestry Studies in China 7:43-46

36. Ma E, Zhao G (2006) Hygroexpansion of wood: from equilibrious state to non-equilibrious state. J Beijing For Univ 28:133

37. Cao J (2001) Interaction between water and wood during adsorption and desorption processes-from dielectric and thermodynamic approaches. Dissertation, Beijing Forestry University
38. Haslach HW (1994) The mechanics of moisture accelerated tensile creep in paper. Tappi 77:179-186

39. Alfthan J (2004) Micro-mechanically Based Modeling of Mechano-Sorptive Creep in Paper. Dissertation, KTH

40. Habeger CC, Coffin DW, Hojjatie B (2001) Influence of humidity cycling parameters on the moisture-accelerated creep of polymeric fibers. J Polym Sci, Part B: Polym Phys 39:2048-2062

41. Gibson EJ (1965) Creep of wood: role of water and effect of a changing moisture content. Nature 206:213-215

42. Takemura T (1966) Plastic properties of wood in relaxation to the nonequilibrium states of moisture content. Memoirs of the college of Agriculture of Kyoto University vol. 88, pp 31-48

43. Takemura T (1967) Plastic properties of wood in relaxation to the nonequilibrium states of moisture content (continued). Mokuzai Gakkaishi 13:163-168

\section{Publisher's Note}

Springer Nature remains neutral with regard to jurisdictional claims in published maps and institutional affiliations.

\section{Submit your manuscript to a SpringerOpen ${ }^{\odot}$ journal and benefit from:}

- Convenient online submission

- Rigorous peer review

- Open access: articles freely available online

- High visibility within the field

- Retaining the copyright to your article

Submit your next manuscript at $\gg$ springeropen.com 